University of Nebraska - Lincoln

DigitalCommons@University of Nebraska - Lincoln

Public Health Resources

Public Health Resources

2008

\title{
Breast Cancer Incidence Among American Indian and Alaska Native Women: US, 1999-2004
}

\author{
Phyllis A. Wingo \\ Centers for Disease Control and Prevention, pwingo@cancer.org \\ Jessica King \\ Centers for Disease Control and Prevention \\ Judith Swan \\ National Cancer Institute, swanj@mail.nih.gov \\ Steven S. Coughlin \\ Centers for Disease Control and Prevention, Atlanta, sic9@cdc.gov \\ Judith S. Kaur \\ Mayo Clinic College of Medicine, kaur.judith@mayo.edu \\ See next page for additional authors
}

Follow this and additional works at: https://digitalcommons.unl.edu/publichealthresources

Part of the Public Health Commons

Wingo, Phyllis A.; King, Jessica; Swan, Judith; Coughlin, Steven S.; Kaur, Judith S.; Erb-Alvarez, Julie A.; Jackson-Thompson, Jeannette; and Arambula Solomon, Teshia G., "Breast Cancer Incidence Among American Indian and Alaska Native Women: US, 1999-2004" (2008). Public Health Resources. 277. https://digitalcommons.unl.edu/publichealthresources/277

This Article is brought to you for free and open access by the Public Health Resources at DigitalCommons@University of Nebraska - Lincoln. It has been accepted for inclusion in Public Health Resources by an authorized administrator of DigitalCommons@University of Nebraska - Lincoln. 


\section{Authors}

Phyllis A. Wingo, Jessica King, Judith Swan, Steven S. Coughlin, Judith S. Kaur, Julie A. Erb-Alvarez, Jeannette Jackson-Thompson, and Teshia G. Arambula Solomon 


\section{An Update on Cancer in American Indians and Alaska Natives, 1999-2004}

Supplement to Cancer

\section{Breast Cancer Incidence Among American Indian and Alaska Native Women: US, 1999-2004}

\author{
Phyllis A. Wingo, PhD, Ms ${ }^{1}$ \\ Jessica King, $\mathrm{MPH}^{1}$ \\ Judith Swan, MHs ${ }^{2}$ \\ Steven S. Coughlin, $\mathrm{PhD}^{1}$ \\ Judith S. Kaur, MD $^{3}$ \\ Julie A. Erb-Alvarez, $\mathrm{MPH}^{4}$ \\ Jeannette Jackson-Thompson, MSPH, $\mathrm{PhD}^{5}$ \\ Teshia G. Arambula Solomon, $\mathrm{PhD}^{6}$ \\ ${ }^{1}$ Division of Cancer Prevention and Control, \\ National Center for Chronic Disease Prevention \\ and Health Promotion, Centers for Disease Con- \\ trol and Prevention, Atlanta, Georgia. \\ ${ }^{2}$ Division of Cancer Control and Population \\ Sciences, National Cancer Institute, Bethesda, \\ Maryland. \\ ${ }^{3}$ Division of Medical Oncology, Mayo Clinic, Col- \\ lege of Medicine, Rochester, Minnesota. \\ ${ }^{4}$ Southern Plains Inter-Tribal Epidemiology Cen- \\ ter, Oklahoma City, Oklahoma. \\ ${ }^{5}$ Missouri Cancer Registry and Department of \\ Health Management and Informatics, University \\ of Missouri-Columbia, Columbia, Missouri. \\ ${ }^{6}$ Department of Family and Community Medi- \\ cine, University of Arizona, Tucson, Arizona.
}

BACKGROUND. Breast cancer is a leading cause of cancer morbidity and mortality among American Indian and Alaska Native (AI/AN) women. Although published studies have suggested that breast cancer rates among AI/AN women are lower than those among other racial and ethnic populations, accurate determinations of the breast cancer burden have been hampered by misclassification of AI/AN race.

METHODS. Cancer incidence data from the National Program of Cancer Registries and the Surveillance, Epidemiology, and End Results Program were combined to estimate age-adjusted rates for the diagnosis years 1999 through 2004. Several steps were taken to reduce the misclassification of $\mathrm{AI} / \mathrm{AN}$ race: linking cases to Indian Health Service (IHS) patient services database, restricting analyses to Contract Health Service Delivery Area counties, and stratifying results by IHS region. RESULTS. Breast cancer incidence rates among AI/AN women varied nearly 3fold across IHS regions. The highest rates were in Alaska (134.8) and the Plains (Northern, 115.9; Southern, 115.7), and the lowest rates were in the Southwest (50.8). The rate in Alaska was similar to the rate among non-Hispanic white (NHW) women in Alaska. Overall, AI/AN women had lower rates of breast cancer than NHW women, but AI/AN women were more likely to be diagnosed with late-stage disease.

CONCLUSIONS. To the authors' knowledge, this report provides the most comprehensive breast cancer incidence data for AI/AN women to date. The wide regional variation indicates an important need for etiologic and health services research, and the large percentage of AI/AN women with late-stage disease demands innovative approaches for increasing access to screening. Cancer 2008;113(5 suppl):1191-202. Published 2008 by the American Cancer Society.*

KEYWORDS: incidence, breast cancer, American Indian/Alaska Native, National Program of Cancer Registries, Surveillance, Epidemiology, and End Results.

D reast cancer is a leading cause of cancer morbidity and mortality among American Indian and Alaska Native (AI/AN) women. ${ }^{1}$ Previous studies have suggested that breast cancer rates are lower

This supplement was sponsored by Cooperative Agreement Number U50 DP424071-04 from the Centers for Disease Control and Prevention, Division of Cancer Prevention and Control.

The findings and conclusions in this report are those of the authors and do not necessarily represent the official position of the Centers for Disease Control and Prevention.
Phyllis A. Wingo is employed by the Arctic Slope Regional Corporation, Inc., which is a contractor to the Indian Health Service.

Address for reprints: Steven S. Coughlin, PhD, Centers for Disease Control, 4770 Buford Highway NE, Chamblee, GA 30341; MS K55; Fax: (770) 488-4639; E-mail: sic9@cdc.gov
*This article is a US Government work and, as such, is in the public domain in the United States of America.

Received May 5, 2008; accepted June 5, 2008. 
among AI/AN women than among women of other racial and ethnic populations in the United States. ${ }^{1-6}$ Accurate descriptions of the occurrence of cancer among AI/AN populations, however, have been hampered by reports from selected geographic areas and by the misclassification of AI/AN race that results in undercounting this population and thus underestimating its disease burden. ${ }^{6,7}$

A nationwide study of breast cancer mortality among AI/AN women living in counties in or near reservation areas indicated that breast cancer death rates generally were lower than the rates among women in the general United States population, especially in the Pacific Coast, Southwest, and East. ${ }^{4}$ However, breast cancer survival among AI/AN women reportedly was lower than among non-Hispanic white (NHW) women in Surveillance, Epidemiology, and End Results (SEER) areas. ${ }^{8,9}$ AI/AN women may have poorer breast cancer survival than NHW women, even after receiving definitive breast cancer therapy. ${ }^{8}$

Race- and region-specific differences in breast cancer incidence may be accounted for in part by differences in established breast cancer risk factors, such as parity, age at first birth, other reproductive and menstrual factors, hormone-replacement therapy, alcohol use, physical activity, and obesity, as well as by differences in socioeconomic status and factors that influence access to care. ${ }^{1,3,10-12} \mathrm{AI} / \mathrm{AN}$ women reportedly are less likely than NHW women to have undergone mammography screening or to have a high school education and are more likely to live below the poverty level. ${ }^{11,12}$ In a study of 156,570 postmenopausal women who participated in the Women's Health Initiative, the age-adjusted hazard ratio for breast cancer among AI/AN women was lower than that for white women, but adjustment for more than 15 breast cancer risk factors attenuated the difference. ${ }^{10}$

In recent years, the population-based cancer surveillance infrastructure in the United States has matured sufficiently to make available high-quality cancer incidence data covering most of the United States population. This report provides the most comprehensive data to date about the occurrence of breast cancer in AI/AN females across 6 geographic regions of the United States.

\section{MATERIALS AND METHODS Cancer Cases}

State-wide and regional population-based cancer registries collect information on new cancer diagnoses in the United States. They participate in the
Centers for Disease Control and Prevention (CDC) National Program of Cancer Registries (NPCR), the National Cancer Institute (NCI) SEER Program, or both. ${ }^{1}$ Primary cancer site and histology data were coded according to the International Classification of Diseases for Oncology edition in use at the time of diagnosis and converted to the 3rd edition. ${ }^{13}$ For the current study, breast cancer incidence data refer to invasive cancers (C500-C509); lymphomas originating in the lymphatic tissue of the breast, other histologies involving hematopoietic diseases, mesotheliomas, and Kaposi sarcomas are excluded (M9590M9989, M9050-M9055, and M9140). In situ cancers were included in selected tabulations. All breast cancer cases that were included in this study were from states that agreed to participate in this supplement and that meet the United States Cancer Statistics standards for high-quality data (Table 1, Fig. 1). ${ }^{1}$

Data on stage of disease spanned changes in SEER Summary Stage coding. Stage was coded according to SEER Summary Stage 1977 rules for diagnosis years 1999 through 2000 and according to SEER Summary Stage 2000 rules for diagnosis years 2001 thorough 2003; collaborative stage data, which were reported first for 2004, were not available for analysis. Stage data for 1999 through 2003 were combined for this analysis, because the differences for breast cancer cases were minimal in comparative analyses of the 2 systems. ${ }^{14,15}$

Coding race for $\mathrm{AI} / \mathrm{AN}$ cancer cases combines information from 2 sources: 1) the multiple-race fields in central cancer registry records and 2) data linkages with the Indian Health Service (IHS) patient registration database. ${ }^{16}$ To identify AI/AN cases that were misclassified as nonnative, all case records from each state were linked with the IHS patient registration database, which contains medical information about AI/AN individuals who are members of federally recognized tribes and who use IHS services. CDC's LinkPlus was used by the states and IHS to perform linkages based on key patient identifiers. ${ }^{17}$ For this report, all cases that were classified as AI/AN in the first race field in the cancer registry record were retained in that category. When the first race field was classified as white or unknown, however, and the IHS linkage variable was positive, the case was reclassified as AI/AN. Additional details about the linkages are available elsewhere. ${ }^{16}$

Contract Health Service Delivery Area (CHSDA) counties and IHS regions were geographic factors that were used to further elucidate the burden of cancer incidence in the AI/AN population. CHSDA counties, in general, contain federally recognized tribal lands or are adjacent to tribal lands. The pro- 
TABLE 1

Female Breast Cancer Incidence by Indian Health Service Region for American Indians/Alaska Natives and Non-Hispanic Whites: United States, $1999-2004^{\mathrm{a}}$

\begin{tabular}{|c|c|c|c|c|c|c|c|c|c|c|c|c|}
\hline \multirow[b]{2}{*}{ IHS Region } & \multicolumn{6}{|c|}{ CHSDA Counties } & \multicolumn{6}{|c|}{ All Counties } \\
\hline & $\begin{array}{l}\text { AI/AN } \\
\text { Count }\end{array}$ & $\begin{array}{l}\text { AI/AN } \\
\text { Rate }^{\text {b }}\end{array}$ & $\begin{array}{l}95 \% \text { CI for } \\
\text { AI/AN Rate }\end{array}$ & $\begin{array}{l}\text { NHW } \\
\text { Rate }^{\text {b }}\end{array}$ & $\begin{array}{l}\text { RR } \\
\left(\text { AI/AN:NHW) }{ }^{\mathrm{c}}\right.\end{array}$ & $\begin{array}{l}95 \% \mathrm{CI} \\
\text { for RR }\end{array}$ & $\begin{array}{l}\text { AI/AN } \\
\text { Count }\end{array}$ & $\begin{array}{l}\text { AI/AN } \\
\text { Rate }^{\text {b }}\end{array}$ & $\begin{array}{l}95 \% \mathrm{CI} \text { for } \\
\text { AI/AN Rate }\end{array}$ & $\begin{array}{l}\text { NHW } \\
\text { Rate }^{\text {b }}\end{array}$ & $\begin{array}{l}\text { RR } \\
\left(^{A I / A N}: N H W\right)^{c}\end{array}$ & $\begin{array}{l}95 \% \mathrm{CI} \\
\text { for RR }\end{array}$ \\
\hline Northern Plains & 541 & 115.9 & $105.9-126.6$ & 130.3 & $0.89^{\mathrm{d}}$ & $0.81-0.97$ & 780 & 95.4 & $88.4-102.8$ & 130.1 & $0.73^{\mathrm{d}}$ & $0.68-0.79$ \\
\hline Alaska $^{\mathrm{e}}$ & 314 & 134.8 & $119.9-151.1$ & 136.5 & 0.99 & $0.87-1.12$ & 314 & 134.8 & 119.9-151.1 & 136.5 & 0.99 & $0.87-1.12$ \\
\hline Southern Plains & 896 & 115.7 & 108.1-123.5 & 129.6 & $0.89^{\mathrm{d}}$ & $0.83-0.96$ & 1013 & 94.0 & 88.2-100.1 & 128.6 & $0.73^{\mathrm{d}}$ & $0.69-0.78$ \\
\hline Pacific Coast & 580 & 74.7 & 68.4-81.4 & 142.6 & $0.52^{\mathrm{d}}$ & $0.48-0.57$ & 753 & 53.5 & $49.5-57.7$ & 145.5 & $0.37^{\mathrm{d}}$ & $0.34-0.40$ \\
\hline East & 139 & 71.4 & $59.7-84.7$ & 133.6 & $0.53^{\mathrm{d}}$ & $0.45-0.63$ & 616 & 43.1 & $39.6-46.7$ & 129.6 & $0.33^{\mathrm{d}}$ & $0.31-0.36$ \\
\hline Southwest & 571 & 50.8 & $46.6-55.2$ & 125.2 & $0.41^{\mathrm{d}}$ & $0.37-0.44$ & 614 & 48.5 & $44.6-52.6$ & 127.7 & $0.38^{\mathrm{d}}$ & $0.35-0.41$ \\
\hline Total & 3041 & 85.3 & $82.2-88.5$ & 134.4 & $0.63^{\mathrm{d}}$ & $0.61-0.66$ & 4090 & 65.5 & $63.4-67.6$ & 131.7 & $0.50^{\mathrm{d}}$ & $0.48-0.51$ \\
\hline
\end{tabular}

Source: Cancer registries in the Centers for Disease Control and Prevention's National Program of Cancer Registries (NPCR) and/or the National Cancer Institute's Surveillance, Epidemiology, and End Results (SEER) Program.

CHSDA indicates Contract Health Service Delivery Area; IHS, Indian Health Service; AI/AN, American Indians/Alaska Natives; CI, confidence interval; RR, rate ratio; NHW, non-Hispanic whites.

${ }^{\text {a }} \mathrm{AI} / \mathrm{AN}$ race is reported by NPCR and SEER registries or through linkage with the IHS patient registration database. AI/AN persons of Hispanic origin are included.

b Rates are per 100,000 persons and are age-adjusted to the 2000 U.S. standard population (19 age groups; Census P25-1130).

${ }^{\mathrm{c}}$ RRs are calculated in SEER*Stat before rounding of rates and may not equal the RRs calculated from rates presented in the table.

d The RR is statistically significant $(P<.05)$.

${ }^{\mathrm{e}}$ Rates and RRs for Alaska in the CHSDA Counties section are the same as those in the All Counties section, because all counties in Alaska are CHSDA counties. Counts less than 6 were suppressed; if no cases were reported, then rates and RRs could not be calculated.

Years of data and registries used: 1999-2004 (41 states and the District of Columbia): Alaska," Alabama, ${ }^{*}$ Arkansas, Arizona, ${ }^{*}$ California, ${ }^{*}$ Colorado, ${ }^{*}$ Connecticut, ${ }^{*}$ the District of Columbia, Delaware, Florida, Georgia, Hawaii, Iowa, ${ }^{*}$ Idaho, ${ }^{*}$ Illinois, Indiana, ${ }^{*}$ Kentucky, Louisiana, ${ }^{*}$ Massachusetts, ${ }^{*}$ Maine, ${ }^{*}$ Michigan, ${ }^{*}$ Minnesota, ${ }^{*}$ Missouri, Montana, ${ }^{*}$ North Carolina, ${ }^{*}$ Nebraska, ${ }^{*}$ New Hampshire, New Jersey, New Mexico, ${ }^{*}$ Nevada, ${ }^{*}$ New York, ${ }^{*}$ Ohio, Oklahoma, ${ }^{*}$ Oregon, ${ }^{*}$ Pennsylvania, ${ }^{*}$ Rhode Island, ${ }^{*}$ Texas, ${ }^{*}$ Utah, ${ }^{*}$ Washington, Wisconsin, ${ }^{*}$ West Virginia, and Wyoming*; 1999 and 2002-2004: North Dakota*; 2001-2004: South Dakota*; 2003-2004: Mississippi* and Virginia; 2004: Tennessee (asterisks indicate states with at least 1 county designated as a CHSDA).

Percentage regional coverage of AI/AN in CHSDA Counties compared with AI/AN in all Counties: Alaska, 100\%; East 13.1\%; Northern Plains, 59\%; Southern Plains, 64.1\%; Pacific Coast, 55.6\%; Southwest, 87.5\%.

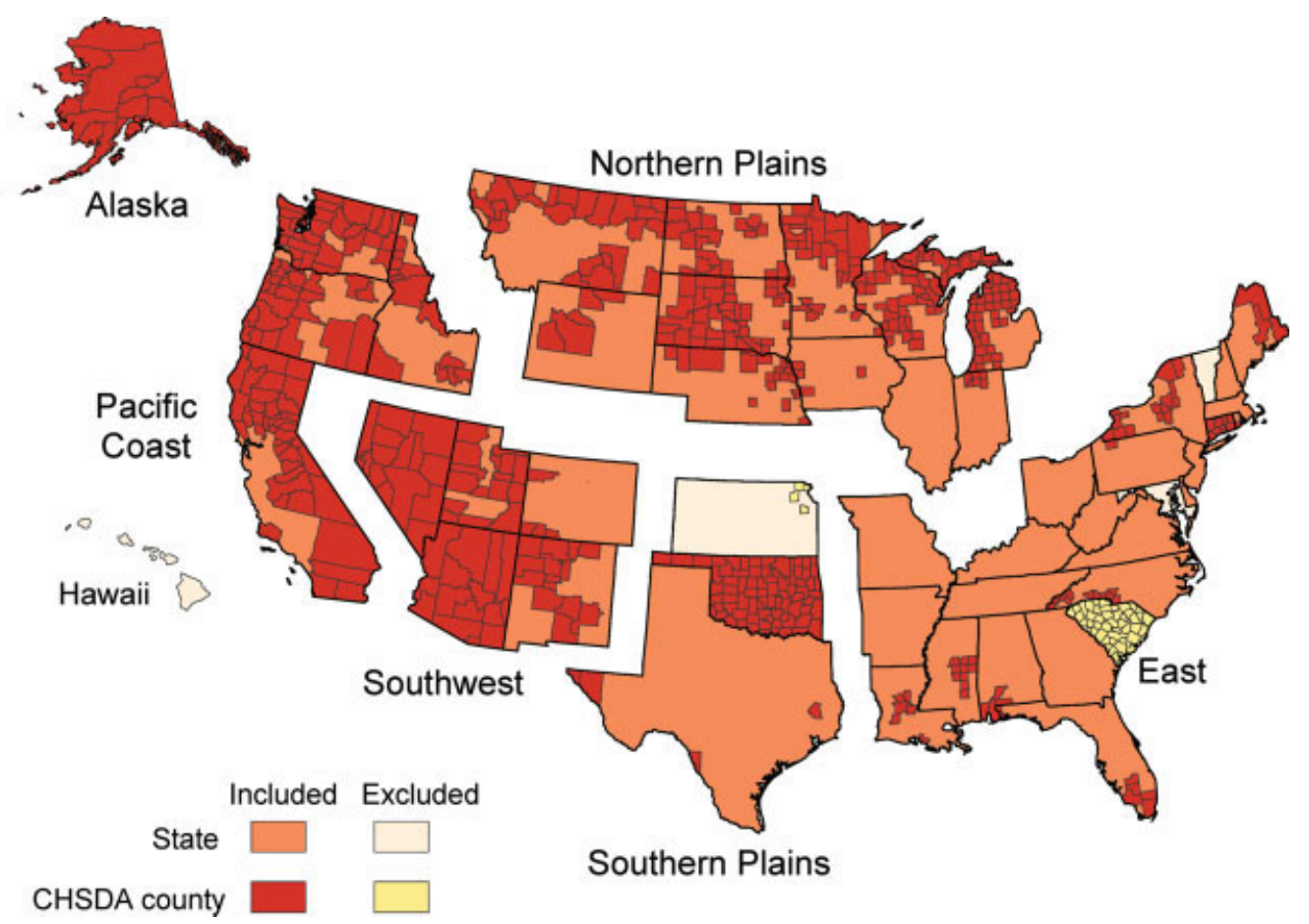

FIGURE 1. This map shows states and Contract Health Service Delivery Area (CHSDA) counties by Indian Health Service region. 
portion of AI/ANs relative to the total population is higher in CHSDA counties with less misclassification than in non-CHSDA counties. ${ }^{18}$ The results described herein refer to individuals who reside in CHSDA counties unless noted otherwise (Fig. 1). The analysis of AI/AN data by IHS region conforms with known regional patterns of specific health outcomes and disease risk factors for AI/ANs. ${ }^{419-21}$ Additional details about CHSDA counties and IHS regions, including population coverage, are provided elsewhere. $^{16}$

\section{Population Estimates}

County level population estimates from the United States Bureau of the Census were used in the denominators of the rate calculations. These population data have been modified in 2 ways: 1) The CDC's National Center for Health Statistics collaborated with the U.S. Bureau of the Census to develop methods for bridging multiple race data, collected since 2000, into single-race annual population estimates, ${ }^{22}$ and 2) the NCI made refinements to race and county codes for use in SEER*Stat software. ${ }^{23,24}$

\section{Statistical Analyses}

For all AI/AN and NHW populations, cancer incidence rates were expressed per 100,000 females and were age-adjusted by 19 age groups $(<1$ year, $1-4$ years, $5-9$ years, ..., 80-84 years, $\geq 85$ years) to the 2000 United States standard population. Rates and 95\% modified $\gamma$ confidence intervals (CIs) were generated by using SEER*Stat software version 6.3. . $^{24,25}$ Percentage distributions also were age-adjusted. Rate ratios with 95\% CIs were provided for regional comparisons of incidence rates between AI/AN and NHW populations (Table 1). The annual percentage change (APC) was used to describe fixed interval trends over time $(P<.05)$; the APC was not analyzed if it was based on $<10$ cases for at least 1 year within the time interval.

\section{RESULTS}

Breast cancer incidence rates among AI/AN women in CHSDA counties varied nearly 3-fold across IHS regions. The highest rates were in Alaska (134.8) and the Plains (Northern, 115.9; Southern, 115.7), and the lowest rates were in the Southwest (50.8). Rates for AI/AN women in CHSDA counties generally were higher than rates for AI/AN women in all counties, except in Alaska and the Southwest. In Alaska, the CHSDA counties rate was equal to the all counties rate, because all counties in Alaska are designated as CHSDA counties. In the Southwest, where most counties are designated as CHSDA, the CHSDA counties rate was similar to the all counties rate.

In contrast, breast cancer incidence rates among NHW women in CHSDA counties did not vary appreciably by region (Table 1). AI/AN rates were lower than NHW rates, with 1 notable exception: The breast cancer incidence rate for AI/AN women in Alaska (134.8), the highest region-specific rate, was nearly identical to the rate for NHW women in Alaska (136.5).

Among AI/AN women in CHSDA counties, the rates of breast cancer generally were higher in Alaska and the Plains regions and lower in the Southwest for each age group (Table 2, Fig. 2). For AI/AN women aged $<50$ years, the rates also were low for the Pacific Coast and East. Like the overall rates, the age-specific rates for AI/AN women varied widely by region, whereas the age-specific rates for NHW women did not (Fig. 2). The average age at breast cancer diagnosis among AI/AN women (57.5 years) was younger than that among NHW women (63.4 years), with $>30 \%$ of AI/AN women aged $<50$ years at diagnosis compared with $19 \%$ of NHW women.

AI/AN women in CHSDA counties were less likely to have their breast cancer diagnosed at an early stage $(61.2 \%)$ than NHW women $(68.6 \%)$ (Table 3 ), and stage distributions varied by region. Among $\mathrm{AI} / \mathrm{AN}$ women, the percentage of early-stage disease ranged from $57.5 \%$ (Southwest) to $66.4 \%$ (Alaska), the percentage of late-stage disease ranged from $23.6 \%$ (Alaska) to $36.1 \%$ (Southwest), and the percentage of unstaged tumors ranged from 3.3\% (Pacific Coast) to $10 \%$ (Alaska).

Stage data were examined further by age at diagnosis (Table 3). In CHSDA counties, the disparity of fewer early-stage diagnoses and more late-stage diagnoses among AI/AN women compared with NHW women was present for both younger women and older women. AI/AN women who were ages 40 to 64 years at diagnosis were more likely to have their cancer diagnosed at a late stage (32.9\%) than older AI/AN women (28.3\%). Older AI/AN females, however, were more likely to have unstaged tumors. Although these same age-stage relations were present for NHW women, the percentages of late-stage disease among NHW women were still lower than those among AI/AN women.

Finally, because recent studies showed declines in breast cancer incidence rates during 1999 through $2003,{ }^{26,27}$ trends were examined for AI/AN women and NHW women in CHSDA counties (Table 4, Fig. 3). Consistent with published reports, rates of breast cancer among NHW women declined significantly by approximately $3 \%$ per year in all regions. In contrast, trends for the smaller AI/AN population were vari- 
TABLE 2

Invasive Female Breast Cancer Incidence Rates by Age and Indian Health Service Region for American Indians/Alaska Natives and Non-Hispanic Whites in Contract Health Service Delivery Area Counties: United States, 1999-2004 ${ }^{\text {a }}$

\begin{tabular}{|c|c|c|c|c|c|c|c|c|c|c|c|c|}
\hline \multirow[b]{2}{*}{ IHS Region } & \multicolumn{3}{|c|}{$<40$ Years } & \multicolumn{3}{|c|}{ 40-49 Years } & \multicolumn{3}{|c|}{ 50-64 Years } & \multicolumn{3}{|c|}{$\geq 65$ Years } \\
\hline & $\%$ of Cases ${ }^{b}$ & Rate $^{\mathrm{a}}$ & $95 \% \mathrm{CI}$ & $\%$ of Cases ${ }^{b}$ & Rate $^{\mathrm{a}}$ & $95 \% \mathrm{CI}$ & $\%$ of Cases ${ }^{b}$ & Rate $^{\mathrm{a}}$ & $95 \% \mathrm{CI}$ & $\%$ of Cases ${ }^{b}$ & Rate $^{\mathrm{a}}$ & $95 \% \mathrm{CI}$ \\
\hline \multicolumn{13}{|l|}{$\mathrm{AI} / \mathrm{AN}$} \\
\hline Northern Plains & 8.7 & 12.4 & $9.1-16.5$ & 24.0 & 137.5 & $114.8-163.2$ & 38.8 & 269.3 & $234.1-308.3$ & 28.5 & 373.9 & $316.1-439.3$ \\
\hline Alaska & 11.8 & 21.5 & $15.1-29.5$ & 24.2 & 171.2 & 134.9-214.3 & 40.8 & 356.2 & 297.0-423.7 & 23.2 & 338.9 & $264.5-428.1$ \\
\hline Southern Plains & 7.3 & 12.9 & $9.9-16.4$ & 18.8 & 126.9 & 108.4-147.6 & 38.2 & 271.6 & $243.5-301.9$ & 35.8 & $380.2^{\mathrm{c}}$ & $339.6-424.3$ \\
\hline Pacific Coast & 6.2 & $5.8^{\mathrm{c}}$ & $4.0-8.0$ & 22.4 & $77.5^{\mathrm{c}}$ & $64.8-92.0$ & 39.7 & $165.0^{c}$ & $144.3-187.9$ & 31.7 & $274.9^{\mathrm{c}}$ & 236.1-318.2 \\
\hline East & 6.5 & $6.3^{\mathrm{c}}$ & $2.9-11.8$ & 17.3 & $63.6^{\mathrm{c}}$ & $40.7-94.6$ & 45.3 & $190.1^{\mathrm{c}}$ & $146.1-243.3$ & 30.9 & $233.9^{\mathrm{c}}$ & $169.0-315.3$ \\
\hline Southwest & 11.0 & $7.2^{\mathrm{c}}$ & $5.5-9.2$ & 25.0 & $69.1^{\mathrm{c}}$ & $58.3-81.4$ & 37.8 & $121.2^{\mathrm{c}}$ & $105.6-138.5$ & 26.1 & $141.0^{\mathrm{c}}$ & $119.0-165.9$ \\
\hline Total & 8.5 & $9.5^{\mathrm{c}}$ & $8.4-10.7$ & 22.1 & $98.0^{\mathrm{c}}$ & $90.8-105.8$ & 39.1 & $201.4^{\mathrm{c}}$ & $190.1-213.2$ & 30.4 & $273.9^{\mathrm{c}}$ & 256.3-292.3 \\
\hline \multicolumn{13}{|l|}{ NHW } \\
\hline Northern Plains & 4.1 & 12.4 & $11.7-13.0$ & 15.2 & 144.7 & $140.9-148.7$ & 33.0 & 299.6 & $294.2-305.1$ & 47.6 & 443.5 & $436.7-450.3$ \\
\hline Alaska & 6.6 & 13.6 & $11.1-16.5$ & 22.6 & 135.9 & $121.9-151.2$ & 43.9 & 332.3 & $307.2-358.9$ & 26.9 & 458.6 & 414.9-505.7 \\
\hline Southern Plains & 3.7 & 12.3 & $11.3-13.4$ & 13.9 & 145.0 & $138.6-151.7$ & 32.9 & 292.1 & $283.6-300.8$ & 49.4 & 447.1 & $436.4-457.9$ \\
\hline Pacific Coast & 3.6 & 12.0 & $11.5-12.5$ & 14.8 & 152.7 & $149.8-155.6$ & 34.3 & 330.1 & $325.9-334.2$ & 47.3 & 496.5 & 491.1-501.9 \\
\hline East & 4.3 & 14.3 & $13.7-15.0$ & 15.0 & 160.2 & $156.5-164.0$ & 31.8 & 302.1 & 297.3-307.0 & 48.9 & 438.5 & $432.8-444.3$ \\
\hline Southwest & 3.8 & 12.1 & $11.4-12.8$ & 13.4 & 136.3 & $131.9-140.7$ & 34.3 & 285.2 & $279.4-291.0$ & 48.5 & 431.6 & $424.3-439.0$ \\
\hline Total & 3.9 & 12.7 & 12.4-13.0 & 14.7 & 149.8 & $148.1-151.5$ & 33.4 & 308.1 & $305.8-310.5$ & 47.9 & 458.3 & $455.4-461.3$ \\
\hline
\end{tabular}

Source: Cancer registries in the Centers for Disease Control and Prevention's National Program of Cancer Registries and/or the National Cancer Institute's Surveillance, Epidemiology, and End Results Program (for the states included, see Table 1).

IHS indicates Indian Health Service; CI, confidence interval; AI/AN, American Indians/Alaska Natives; NHW, non-Hispanic whites.

${ }^{a}$ Rates are per 100,000 persons and are age-adjusted to the 2000 U.S. standard population (19 age groups; Census P25-1130).

$\mathrm{b}$ Percentages may not add to $100 \%$ because of rounding.

c The AI/AN rate is statistically significantly lower than the NHW rate $(P<.05)$.
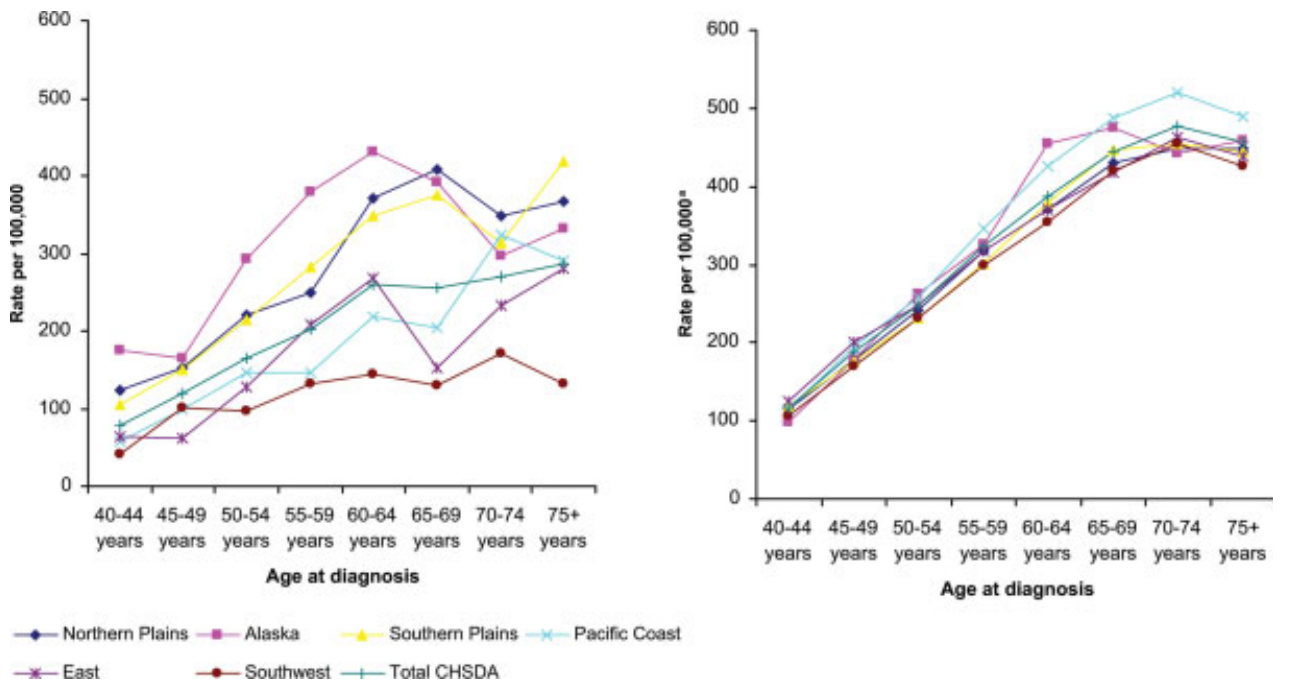

FIGURE 2. These charts illustrate invasive female breast cancer incidence rates by age and by Indian Health Service region for American Indians/Alaska Natives (left) and non-Hispanic whites (right) in Contract Health Service Delivery Area (CHSDA) counties in the United States from 1999 through 2004. Rates are per 100,000 persons and are age-adjusted to the 2000 United States standard population (19 age groups; Census P25-1130).

able but approximately level, except for the trends among AI/AN women in Alaska, which appeared to increase, and in the East, which appeared to decrease. No trend among AI/AN women, however, achieved statistical significance.

\section{DISCUSSION}

The combined NPCR and SEER breast cancer incidence data for AI/AN females in this report are more comprehensive and cover a greater proportion of the AI/AN population than previous publications. Breast 
TABLE 3

Invasive and In Situ Female Breast Cancer, Summary Stage Distribution by Age and Indian Health Service Region for American Indians/Alaska Natives and Non-Hispanic Whites in Contract Health Service Delivery Area Counties: United States, 1999-2003 ${ }^{\mathrm{a}}$

\begin{tabular}{|c|c|c|c|c|c|c|c|c|c|}
\hline \multirow[b]{2}{*}{ IHS Region } & \multicolumn{3}{|c|}{ All Ages Combined } & \multicolumn{3}{|c|}{ 40-64 Years } & \multicolumn{3}{|c|}{$\geq 65$ Years } \\
\hline & $\begin{array}{l}\text { Early }^{\mathrm{b}} \\
\% \text { of Cases }\end{array}$ & $\begin{array}{l}\text { Late }^{\mathrm{c}} \\
\% \text { of Cases }\end{array}$ & $\begin{array}{l}\text { Unstaged } \\
\% \text { of Cases }\end{array}$ & $\begin{array}{l}\text { Early }{ }^{\mathrm{b}} \\
\% \text { of Cases }\end{array}$ & $\begin{array}{l}\text { Late }^{\mathrm{c}} \\
\% \text { of Cases }\end{array}$ & $\begin{array}{l}\text { Unstaged } \\
\% \text { of Cases }{ }^{\mathrm{d}}\end{array}$ & $\begin{array}{l}\text { Early }^{\mathrm{b}} \\
\% \text { of Cases }\end{array}$ & $\begin{array}{l}\text { Late }^{\mathrm{c}} \\
\% \text { of Cases }\end{array}$ & $\begin{array}{l}\text { Unstaged } \\
\% \text { of Cases }\end{array}$ \\
\hline \multicolumn{10}{|l|}{$\mathrm{AI} / \mathrm{AN}$} \\
\hline Northern Plains & 61.4 & 31.2 & 7.3 & 58.1 & 36.0 & 6.0 & 66.6 & 24.4 & 9.0 \\
\hline Alaska & 66.4 & 23.6 & 10.0 & 66.4 & 24.7 & 8.9 & 72.9 & 15.9 & 11.3 \\
\hline Southern Plains & 59.1 & 32.2 & 8.6 & 62.1 & 31.8 & 6.1 & 57.9 & 29.7 & 12.4 \\
\hline Pacific Coast & 64.0 & 32.7 & 3.3 & 64.7 & 33.3 & 1.9 & 63.6 & 31.4 & 5.0 \\
\hline East & 64.1 & 32.0 & 3.9 & 59.4 & 34.5 & 6.2 & 71.7 & 26.3 & 2.0 \\
\hline Southwest & 57.5 & 36.1 & 6.4 & 57.0 & 36.6 & 6.4 & 60.3 & 33.7 & 6.0 \\
\hline Total & 61.2 & 31.8 & 7.0 & 61.5 & 32.9 & 5.6 & 62.8 & 28.3 & 8.8 \\
\hline \multicolumn{10}{|l|}{ NHW } \\
\hline Northern Plains & 68.5 & 26.5 & 5.0 & 68.4 & 27.8 & 3.8 & 70.2 & 23.0 & 6.8 \\
\hline Alaska & 66.2 & 29.9 & 3.9 & 65.7 & 31.4 & 3.0 & 68.7 & 26.1 & 5.1 \\
\hline Southern Plains & 66.0 & 28.4 & 5.5 & 65.1 & 30.6 & 4.3 & 68.8 & 24.0 & 7.2 \\
\hline Pacific Coast & 69.9 & 28.0 & 2.2 & 68.2 & 30.4 & 1.4 & 73.4 & 23.3 & 3.2 \\
\hline East & 69.5 & 25.3 & 5.3 & 69.3 & 26.7 & 4.0 & 71.6 & 21.3 & 7.1 \\
\hline Southwest & 65.8 & 27.6 & 6.5 & 64.6 & 29.9 & 5.5 & 68.8 & 23.5 & 7.8 \\
\hline Total & 68.6 & 27.0 & 4.3 & 67.8 & 29.0 & 3.2 & 71.4 & 22.9 & 5.8 \\
\hline
\end{tabular}

Source: Cancer registries in the Centers for Disease Control and Prevention's National Program of Cancer Registries and/or the National Cancer Institute's Surveillance, Epidemiology, and End Results (SEER) Program (for the states included, see Table 1).

IHS indicates Indian Health Service; CI, confidence interval; AI/AN, American Indians/Alaska Natives; NHW, non-Hispanic white.

${ }^{a}$ For 1999-2000, SEER Summary Stage 1977 was used; for 2001-2003, SEER Summary Stage 2000 was used. Data for the 2 staging systems were combined, because the differences observed in comparative analyses were minimal (see Howe $2005^{14}$ and Phillips $2003^{15}$ ).

${ }^{\mathrm{b}}$ Early includes in situ and local stage disease.

${ }^{\mathrm{c}}$ Late includes regional and distant-stage disease.

${ }^{\mathrm{d}}$ Percentage stage distribution is age-adjusted to the 2000 U.S. standard population (19 age groups; Census P25-1130) and may not add to $100 \%$ because of rounding.

cancer incidence rates among AI/AN women varied nearly 3 -fold across IHS regions, with the highest rates in Alaska and the Plains and the lowest rates in the Southwest. The rate in Alaska was equivalent to the rate among NHW women in Alaska. Overall, AI/ AN women had lower rates of breast cancer than NHW women, but AI/AN females had more advanced disease.

The overall lower rates of breast cancer among AI/AN women compared with women of other racial and ethnic populations and the higher rates of breast cancer among AI/AN women residing in Alaska and states in the Northern and Southern Plains have been observed previously in national and state level statistics. ${ }^{1-3,5,6,28,29}$ For 2004, the United States Cancer Statistics reported breast cancer incidence rates among AI/AN women of 58.3 in New Mexico, 103.6 in Oklahoma, and 149.5 in Alaska. ${ }^{1}$ A study that was restricted to Indian females in Alaska and New Mexico noted rates of 52 among New Mexico Indian women and 233 among Alaskan Indian women (Eskimo and Aleut women were excluded). ${ }^{29}$ Such large regional differences indicate an important need for etiologic and health services research about breast cancer in AI/AN populations. The Four-Corners Breast and Endometrial Cancer Study (Arizona, New Mexico, Colorado, and Utah-all in the Southwest IHS region), for example, was designed to examine genetic admixture in relation to gene markers and environmental factors among American Indian, Hispanic, and NHW women..$^{30,31}$ Studies of breast cancer risk factors and genetic markers also are needed among AI/AN populations in other regions. In Alaska, for example, widespread exposure to organochlorines has been documented, buts its association with breast cancer is uncertain. ${ }^{32}$

The wide variation in AI/AN breast cancer incidence rates by IHS region may be influenced by many factors, such as differences in sociodemographic population characteristics (eg, urban or rural residence), access to healthcare and use of mammography screening, reproductive behaviors (eg, parity, breast feeding, age at first full-term pregnancy), other health-related behaviors (eg, diet, physical activity), environmental exposures, misclassification of AI/ AN race, or registry operations (eg, case completeness, 
TABLE 4

Invasive Female Breast Cancer Rates by Year of Diagnosis and Indian Health Service Region for American Indians/Alaska Natives and Non-Hispanic Whites in Contract Health Service Delivery Area Counties: United States, 1999-2004 ${ }^{\mathrm{a}}$

\begin{tabular}{|c|c|c|c|c|c|c|c|c|c|c|c|c|c|}
\hline \multirow[b]{3}{*}{ IHS Region } & \multicolumn{13}{|c|}{ Year of Diagnosis } \\
\hline & \multicolumn{2}{|r|}{1999} & \multicolumn{2}{|r|}{2000} & \multicolumn{2}{|r|}{2001} & \multicolumn{2}{|r|}{2002} & \multicolumn{2}{|r|}{2003} & \multicolumn{2}{|c|}{2004} & \multirow[b]{2}{*}{$\mathrm{APC}$} \\
\hline & Rate $^{a}$ & $95 \% \mathrm{CI}$ & Rate $^{a}$ & $95 \% \mathrm{CI}$ & Rate $^{\mathrm{a}}$ & $95 \% \mathrm{CI}$ & Rate $^{\mathrm{a}}$ & $95 \% \mathrm{CI}$ & Rate $^{\mathrm{a}}$ & $95 \% \mathrm{CI}$ & Rate $^{a}$ & $95 \% \mathrm{CI}$ & \\
\hline \multicolumn{14}{|l|}{ AI/AN } \\
\hline Northern Plains & 114.8 & $87.4-147.6$ & 127.3 & $98.7-161.3$ & 105.0 & 82.1-131.9 & 125.9 & $102.2-153.1$ & 124.1 & $101.2-150.3$ & 102.6 & $82.6-125.8$ & -1.4 \\
\hline Alaska & 87.4 & $58.8-124.6$ & 149.0 & $112.5-193.3$ & 128.0 & $94.3-169.5$ & 123.9 & $89.6-166.5$ & 166.4 & $127.7-212.7$ & 145.9 & $110.5-188.6$ & 6.8 \\
\hline Southern Plains & 129.3 & 109.3-151.7 & 112.3 & $94.1-132.8$ & 126.2 & $107.3-147.3$ & 117.5 & $99.5-137.7$ & 113.0 & $95.7-132.5$ & 99.5 & $83.6-117.6$ & -3.8 \\
\hline Pacific Coast & 73.9 & $58.4-92.0$ & 67.6 & $53.0-84.8$ & 88.0 & 71.3-107.3 & 86.0 & $70.1-104.2$ & 60.5 & $47.8-75.5$ & 72.0 & $58.0-88.3$ & -1.4 \\
\hline East & 93.7 & $60.1-138.2$ & 58.4 & $34.1-92.9$ & 77.6 & 48.4-117.0 & 75.9 & $47.9-113.5$ & 80.2 & $53.0-115.9$ & 48.6 & $28.9-76.3$ & -6.3 \\
\hline Southwest & 62.1 & $50.0-76.1$ & 53.3 & $42.8-65.5$ & 45.0 & $35.6-55.9$ & 44.5 & $35.4-55.2$ & 48.9 & $39.5-59.8$ & 52.5 & $42.8-63.5$ & -3.0 \\
\hline Total & 90.1 & $81.8-99.0$ & 84.8 & $77.0-93.1$ & 87.2 & $79.5-95.3$ & 87.7 & $80.2-95.7$ & 84.6 & $77.5-92.3$ & 79.3 & $72.5-86.5$ & -1.8 \\
\hline \multicolumn{14}{|l|}{ NHW } \\
\hline Northern Plains & 138.2 & $134.7-141.8$ & 136.8 & 133.3-140.4 & 136.9 & 133.4-140.4 & 132.9 & $129.5-136.3$ & 121.3 & $118.1-124.5$ & 117.8 & $114.7-121.0$ & $-3.3^{\mathrm{b}}$ \\
\hline Alaska & 145.7 & $126.7-166.6$ & 156.7 & $137.3-178.0$ & 139.6 & $121.9-159.1$ & 132.6 & $115.7-151.3$ & 136.4 & $119.4-155.1$ & 111.4 & 96.4-128.1 & $-4.9^{\mathrm{b}}$ \\
\hline Southern Plains & 134.7 & $129.2-140.4$ & 131.8 & 126.4-137.4 & 133.8 & $128.4-139.5$ & 128.3 & $123.0-133.8$ & 122.4 & $117.2-127.8$ & 127.0 & $121.7-132.4$ & $-1.6^{\mathrm{b}}$ \\
\hline Pacific Coast & 151.2 & $148.5-154.0$ & 147.6 & $144.9-150.3$ & 148.5 & $145.9-151.2$ & 144.7 & $142.1-147.3$ & 134.3 & $131.9-136.9$ & 130.1 & $127.7-132.6$ & $-3.0^{\mathrm{b}}$ \\
\hline East & 142.7 & $139.6-145.9$ & 137.5 & $134.4-140.6$ & 141.1 & $138.0-144.2$ & 131.7 & $128.7-134.8$ & 126.5 & $123.6-129.5$ & 123.0 & $120.2-126.0$ & $-3.0^{\mathrm{b}}$ \\
\hline Southwest & 129.4 & $125.6-133.3$ & 134.1 & $130.3-138.0$ & 133.8 & $130.0-137.6$ & 129.1 & $125.4-132.8$ & 115.4 & $112.0-118.9$ & 111.3 & $107.9-114.7$ & $-3.5^{\mathrm{b}}$ \\
\hline Total & 142.1 & $140.6-143.7$ & 139.9 & $138.4-141.4$ & 141.2 & $139.7-142.7$ & 135.6 & $134.1-137.1$ & 126.2 & $124.8-127.6$ & 122.7 & $121.3-124.1$ & $-3.0^{\mathrm{b}}$ \\
\hline
\end{tabular}

Source: Cancer registries in the Centers for Disease Control and Prevention's National Program of Cancer Registries and/or the National Cancer Institute's Surveillance, Epidemiology, and End Results Program (for the states included, see Table 1).

IHS indicates Indian Health Service; CI, confidence interval; APC, annual percentage change; AI/AN, American Indians/Alaska Natives; NHW, non-Hispanic whites.

${ }^{a}$ Rates are per 100,000 and are age-adjusted to the 2000 U.S. standard population (19 age groups; Census P25-1130).

${ }^{\mathrm{b}} \mathrm{APC}$ is statistically significant $(P<.05)$.
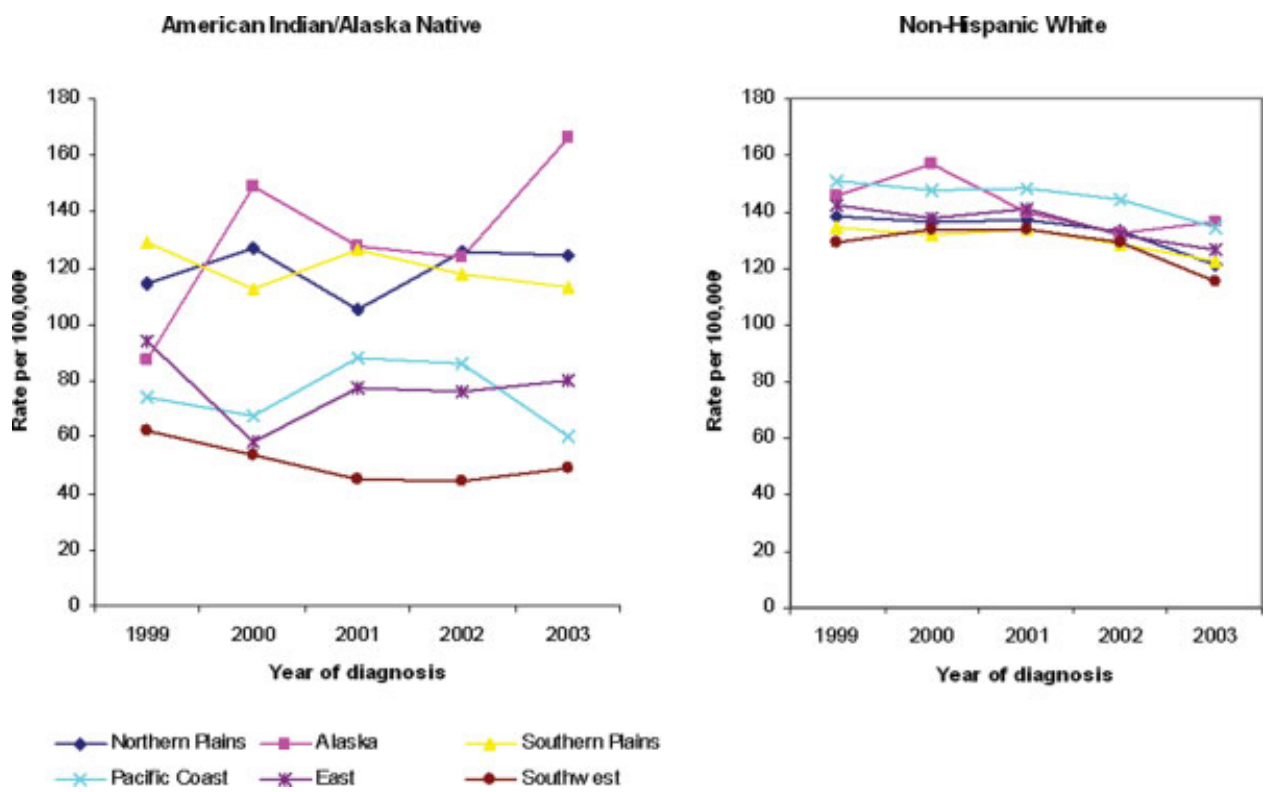

FIGURE 3. These charts illustrate invasive female breast cancer incidence rates by year and by Indian Health Service region for American Indians/Alaska Natives (left) and non-Hispanic whites (right) in Contract Health Service Delivery Area (CHSDA) counties in the United States from 1999 through 2004. Rates are per 100,000 persons and are age-adjusted to the 2000 United States standard population (19 age groups; Census P25-1130). 
timeliness). Generally, these factors do not appear to explain the 3-fold variation, and data for making regional comparisons of risk factors among AI/AN women are limited. Results from the Strong Heart Study (Arizona, Oklahoma, North Dakota, and South Dakota) and the Women's Health Initiative (national) indicated that AI/AN women were more likely than white women to have large families (5 or more fullterm pregnancies), ${ }^{10,33}$ and, although the numbers were small, AI/AN women tended to be younger at the birth of their first child. ${ }^{10}$ Analyses from the 2000 through 2006 Behavioral Risk Factor Surveillance System indicated wide regional variations in other breast cancer risk factors. ${ }^{34}$ For example, among AI/AN women, prevalence estimates for obesity ranged from $25 \%$ in the East to $34 \%$ in Alaska; no leisuretime physical activity ranged from $28 \%$ in the Southwest to between $35 \%$ and $38 \%$ in Alaska and the East; and binge drinking ranged from $14 \%$ in Alaska to about $7 \%$ in the East, Southwest, and Pacific Coast. Only Alaska reported AI/AN mammography prevalence estimates equivalent to those for NHW women; nationally and in other regions, mammography screening during the previous 2 years was lower among AI/AN women than among NHW females (69\% vs $76 \%$, respectively, among women aged $\geq 40$ years).

According to data from the Behavioral Risk Factor Surveillance System, AI/AN respondents are more likely than NHW respondents to have lower incomes, less education, higher unemployment, no health insurance, and no personal physician. ${ }^{34}$ These and other factors inhibit access to care, such as not having health insurance (ie, currently, approximately $30 \%$ of AI/ANs lack health insurance), ${ }^{35}$ membership in tribes that are not recognized by the federal government, urban residence (ie, approximately $70 \%$ of AI/ANs live in urban areas), ${ }^{36,37}$ and long distances to travel to receive care. ${ }^{38,39}$ More specifically, although the IHS provides medical services to AI/AN individuals who are members of more than 560 federally recognized tribes, care is not readily accessible to AI/AN individuals who are members of tribes that are not recognized by the federal government, ${ }^{2}$ and only about $10 \%$ of the urban Indian population can access IHS services. ${ }^{39}$ Many AI/ANs who reside in urban areas receive their diagnosis in urban settings but then must migrate back to reservation areas to access care through the IHS and other tribal facilities. $^{38,39}$ For example, $43 \%$ of Colorado's AI/AN population lives in Denver, but the closest IHS facility is 390 miles away. ${ }^{39}$

Several programs have been developed to increase mammography screening among $\mathrm{AI} / \mathrm{AN}$ women. The IHS began cervical cancer screening in the 1960s and 1970s, and declines in cervical cancer incidence and mortality rates followed in the 1980s and 1990s. ${ }^{40,41}$ Little mammography screening, however, was being provided to this population before the establishment of the CDC's National Breast and Cervical Cancer Early Detection Program. ${ }^{42}$

Fourteen tribal programs, in addition to all 50 states, currently receive support from this program to build infrastructure and provide screening services. (The 14 tribal programs are Arctic Slope Native Association Limited, Barrow, Alaska; Cherokee Nation, Tahlequah, Okla; Cheyenne River Sioux Tribe, Eagle Butte, SD; Hopi Tribe, Kykotsmovi, Ariz; Kaw Nation of Oklahoma, Newkirk, Okla; Mississippi Band of Choctaw Indians, Choctaw, Miss; Native American Rehabilitation Association of the Northwest, Portland, Ore; Navajo Nation, Window Rock, Ariz; Poarch Band of Creek Indians, Atmore, Ala; South East Alaska Regional Health Consortium, Sitka, Alaska; South Puget Intertribal Planning Agency, Shelton, Wash; Southcentral Foundation, Anchorage, Alaska; and Yukon-Kuskokwim Health Corporation, Bethel, Alaska.) Despite such efforts, AI/AN females still have a low prevalence of mammography screening. Systematic reviews have identified communityand provider-based interventions that are effective in promoting mammography screening in diverse populations. ${ }^{43}$ Examples include client reminders, 1on-1 education, and provider assessment and feedback. Replication research may be helpful for tailoring such evidence-based intervention approaches to AI/AN populations, particularly those that reside in rural areas and those that have long distances to travel. For example, during March through July 2006, a mobile mammography truck visited Aberdeen Area IHS clinics in the Dakotas and provided more than 500 digital mammograms. ${ }^{44}$ The digital images were transmitted and reviewed by radiologists at the University of Michigan within 1 hour of receipt. Women watched culturally appropriate health-related videos or sought other screening examinations while waiting for their results. Because of the rapid telemedicine review, the majority of women who needed additional images received them the same day and avoided traveling long distances another day.

In the current study, on average, AI/AN women were diagnosed with breast cancer at a younger age than NHW women; $30 \%$ of AI/AN women were diagnosed before age 50 years compared with $19 \%$ of NHW women. The difference between the age distributions for AI/AN women and NHW women reflects the age structures of the younger AI/AN population and the older NHW population. The age-specific 
rates for AI/AN women generally were lower than for NHW women, with several exceptions by region. Age-specific rates for AI/AN women were similar to those for NHW women in Alaska and the Plains regions. Nonetheless, previous studies have demonstrated that women who are diagnosed with breast cancer at a young age, usually before age 40 years, have poorer survival than women who are diagnosed at older ages, probably because of later stage at diagnosis, larger tumors, and higher grade tumors. ${ }^{45,46}$ Moreover, selected risk factors (eg, black race and high parity) have been associated with an increased risk of developing breast cancer at young ages but with a decreased risk when diagnosed at older ages, when most breast cancers occur. ${ }^{46-49}$ Large body mass index is associated with a lower risk in premenopausal women and with an elevated risk in postmenopausal women. ${ }^{48}$

From the early 1980s through 1991, breast cancer incidence rates for women of all racial and ethnic populations combined have increased about $0.4 \%$ per year. ${ }^{2}$ Reports about AI/AN women in Alaska indicate that rates have been increasing for 25 years. ${ }^{50,51}$ More recently, from 2001 through 2004, United States and SEER breast cancer incidence rates declined precipitously, about $3.9 \%$ per year, in part because women stopped receiving hormone-replacement therapy. ${ }^{26,27}$ The declines were observed for all racial and ethnic populations except AI/AN women. Similarly, in the current analysis, incidence rates for NHW women decreased significantly from 2001 through 2003, whereas the rates for AI/AN women overall were stable. The rate in Alaska appeared to increase, but the APC did not achieve statistical significance. Application of the Gail model to AI/AN women who had had mammography in Alaska, Arizona, and South Dakota predicted that breast cancer rates among Alaskan AI/AN women would increase to between 170 and 180, higher than the rate for white women. ${ }^{52}$ Increased rates also were predicted for AI/AN women in South Dakota, and more slowly increasing rates seemed likely for AI/AN women in Arizona.

Possible reasons for the trend differences between AI/AN women and NHW women are complex and probably involve more than stopping hormone-replacement therapy. Regardless, except for 1 study, data about AI/AN women using hormones to treat menopausal symptoms are limited. ${ }^{33}$ The Strong Heart Study, which was conducted among AI/ AN women in Arizona, Oklahoma, and the Dakotas in the early 1990s, reported estimates of current hormone-replacement therapy in perimenopausal and postmenopausal women that ranged from $5 \%$ in Arizona to $21 \%$ in Oklahoma. It is likely that the per- centage of AI/AN women who use hormonereplacement therapy is very low. AI/AN women may not request hormone-replacement therapy or may use traditional medicines to treat the symptoms of menopause.

The patterns of breast cancer stage in the current study have potential importance for public health practice. Of particular concern are the large percentages of AI/AN women diagnosed with advanced breast cancer. Stage can be a useful marker of inadequate screening mammography services at the population level. Previous studies have identified several factors associated with late stage at breast cancer diagnosis, including failure to adhere to mammography screening guidelines, age, less education, race, Hispanic ethnicity, and factors associated with decreased access to care (eg, lower income, residence in socioeconomically distressed counties, high population density, rural residence, residence in medically underserved urban areas, and lack of healthcare insurance or underinsurance). ${ }^{53-57}$ Clinically, stage is used to assess prognosis, plan treatment, and evaluate outcomes. ${ }^{58}$ The policy for the CDC's National Breast and Cervical Cancer Early Detection Program, which restricts the percentage of women aged $<50$ years who can be screened to $25 \%,{ }^{42}$ needs to be reviewed carefully, considering the high percentage of AI/AN women aged $<50$ years $(30 \%)$ who are diagnosed with breast cancer.

The cancer surveillance infrastructure in the United States now provides cancer incidence data for most of the population by site, sex, race and Hispanic origin. ${ }^{2}$ Several limitations in data collection and analysis, however, may influence the interpretation of results in this report. Previous studies have demonstrated that many AI/ANs were misclassified as another race in cancer registry data and that the extent of misclassification varied by registry, ranging from $36 \%$ (Minnesota) to $57 \%$ (California). ${ }^{59-64}$ Although linkages between cancer registry data and the IHS patient registration database improve the race classification for AI/AN cases in the numerator of the rate calculations, the issue is not resolved completely, because AI/AN individuals who are not members of the federally recognized tribes, who live primarily in urban settings, who live long distances from IHS facilities, who live in counties other than those designated as CHSDA, or who are not eligible for IHS services are underrepresented in the IHS database. In contrast, the denominators used in the rate calculations are derived from United States census population estimates and are based on self-identification of race, which is preferred as the most accurate classification. With greater misclassification 
of race in the numerator and presumably less in the denominator, the actual rates for AI/ANs may be higher than those reported in the current study. Additional details about the misclassification of AI/ AN race are available elsewhere in this supplement. ${ }^{16}$

The analyses presented here for AI/AN populations are based on residents of CHSDA counties, which cover $56 \%$ of the AI/AN population in the United States, and exclude many AI/AN residents in urban areas. Therefore, the findings likely do not represent all AI/AN populations in the United States or in individual IHS regions. In particular, the East region includes only $13.1 \%$ of the total AI/AN population residing there. ${ }^{16}$

In summary, this report provides a more comprehensive picture of the breast cancer burden for AI/AN women than has been available previously. Breast cancer incidence rates for AI/AN women vary nearly 3-fold across the IHS regions in the United States, and AI/AN women are more likely to have advanced-stage disease than NHW women. Although many efforts are underway to expand access to care, serious challenges remain with providing sufficient diagnostic and treatment capacity to accommodate women with positive mammography examinations and females with new breast cancer diagnoses. The large percentage of late-stage diagnoses can be reduced only with new and innovative approaches tailored to increase mammography screening among AI/AN females. The 3-fold regional variation in breast cancer rates cannot be explained completely by the variations in breast cancer risk factors and signifies a need for etiologic and health services research into the underlying risk factors in AI/AN women. Finally, the large percentage of AI/AN women diagnosed before age 50 years underscores the importance of studying genetic markers.

\section{REFERENCES}

1. U.S. Cancer Statistics Working Group. United States Cancer Statistics: 2004 Incidence and Mortality. Atlanta, Ga: U.S. Department of Health and Human Services, Centers for Disease Control and Prevention and National Cancer Institute; 2007.

2. Espey DK, Wu XC, Swan J, et al. Annual report to the nation on the status of cancer, 1975-2004, featuring cancer in American Indians and Alaska Natives. Cancer. 2007;110: 2119-2152.

3. Joslyn SA, Foote ML, Nasseri K, Coughlin SS, Howe HL. Racial and ethnic disparities in breast cancer rates by age: NAACCR breast cancer project. Breast Cancer Res Treat. 2005;92:97-105.

4. Espey D, Paisano R, Cobb N. Regional patterns and trends in cancer mortality among American Indians and Alaska Natives, 1990-2001. Cancer. 2005;103:1045-1053.
5. Paltoo DN, Chu KC. Patterns in cancer incidence among American Indians/Alaska Natives, United States, 1992-1999. Public Health Rep. 2004;119:443-451.

6. Swan J, Edwards BK. Cancer rates among American Indians and Alaska Natives: is there a national perspective? Cancer. 2003;98:1262-1272.

7. Puukka E, Stehr-Green P, Becker TM. Measuring the health status gap for American Indians/Alaska Natives: getting closer to the truth. Am J Public Health. 2005;95:838-843.

8. Wampler NS, Lash TL, Silliman RA, Heeren TC. Breast cancer survival of American Indian/Alaska Native women, 1973-1996. Soz Praventivmed. 2005;50:230-237.

9. Clegg LX, Lie FP, Hankey BF, Chu K. Cancer survival among U.S. whites and minorities: a SEER Program populationbased study. Arch Intern Med. 2002;162:1985-1993.

10. Chlebowski RT, Chen Z, Anderson GL, et al. Ethnicity and breast cancer: factors influencing differences in incidence and outcome. J Natl Cancer Inst. 2005;97:439-448.

11. Smith-Bindman R, Miglioretti DL, Lurie N, et al. Does utilization of screening mammography explain racial and ethnic differences in breast cancer? Ann Intern Med. 2006; 144:541-553.

12. Ward E, Jemal A, Cokkinides V, et al. Cancer disparities by race/ethnicity and socioeconomic status. CA Cancer J Clin. 2004;54:78-93.

13. Fritz A, Percy C, Jack A, et al., editors. International Classification of Diseases for Oncology. Geneva, Switzerland: World Health Organization; 2000.

14. Howe HL, Jamison PM, Havener L, Chen VW, Ries LAG. SiteSpecific Comparison of Summary Stage 1977 and Summary Stage 2000 Coding. Springfield, Ill: North American Association of Central Cancer Registries; 2005. Available at: http://www. naaccr.org/index.asp?Col_SectionKey=11\&Col_ContentID $=397$. Accessed on July 9, 2008.

15. Phillips JL, ed. Summary Stage: Data Effects of the Changes in 2000. Springfield, Ill: North American Association of Central Cancer Registries; 2003. Available at: http://www. naaccr.org/filesystem/pdf/Summary\%20Stage\%20Report\% 201-21-04b.pdf. Accessed on July 9, 2008.

16. Espey DK, Wiggins CL, Jim MA, Miller BA, Johnson CJ, Becker TM. Methods for improving cancer surveillance data in American Indian and Alaska Native populations. Cancer. 2008;113(5 suppl):1120-1130.

17. Centers for Disease Control and Prevention. Link Plus: A Suite of Publicly Available Software Programs for Collecting and Processing Cancer Registry Data. Atlanta, Ga: Centers for Disease Control and Prevention, National Center for Chronic Disease Prevention and Health Promotion, U.S. Department of Health and Human Services; 2005. Available at: http://www.cdc.gov/cancer/npcr/tools/registryplus/lp.htm. Accessed on July 9, 2008.

18. Jim MA, Espey DK, Wiggins C, Cobb N, Wingo PA. Racial Misclassification of American Indians Residing Near IHS Facilities: Poster P-47, Final Program and Abstracts. Presented at the 2006 North American Association of Central Cancer Registries Conference, Regina, Saskatchewan, Canada, June 10-16, 2006.

19. Cobb N, Paisano RE. Patterns of cancer mortality among Native Americans. Cancer. 1998;83:2377-2383.

20. Espey DK, Paisano RE, Cobb N. Cancer Mortality among American Indians and Alaska Natives: Regional Differences, 1994-1998. Rockville, Md: Indian Health Services; 2003.

21. Denny CH, Holtzman D, Cobb N. Surveillance for health behaviors of American Indians and Alaska Natives. Find- 
ings from the Behavioral Risk Factor Surveillance System, 1997-2000. MMWR Surveill Summ. 2003;52:1-13.

22. Ingram DD, Parker JD, Schenker $\mathrm{N}$, et al. United States Census 2000 population with bridged race categories. Vital Health Stat 2. 2003;(135):1-55.

23. National Cancer Institute. Surveillance, Epidemiology, and End Results (SEER) Program Statistical Resources. U.S. Population Data 1969-2004. Bethesda, Md: National Cancer Institute. Available at: http://seer.cancer.gov/popdata. Accessed on July 9, 2008.

24. Surveillance Research Program. SEER*Stat Software. Bethesda, Md: National Cancer Institute; 2007. Available at: http://www.seer.cancer.gov/seerstat. Accessed on July 9, 2008.

25. Tiwari RC, Clegg LX, Zou Z. Efficient interval estimation for age-adjusted cancer rates. Stat Methods Med Res. 2006; 15:547-569.

26. Stewart SL, Sabatino SA, Foster SL, Richardson LC. Decline in breast cancer incidence-United States, 1999-2003. MMWR Wkly Rep. 2007;56:549-553.

27. Ravdin PM, Cronin KA, Howlader N, et al. The decrease in breast-cancer incidence in 2003 in the United States. $N$ Engl J Med. 2007;16:1670-1674.

28. Ries LAG, Eisner MP, Kosary CL, et al., editors. SEER Cancer Statistics Review, 1973-2004. Bethesda Md: National Cancer Institute; 2007. Available at: http://www.seer.cancer.gov/csr/1973_2004. Accessed on July 9, 2008.

29. Kelly JJ, Lanier AP, Alberts S, Wiggins CL. Differences in cancer incidence among Indians in Alaska and New Mexico and U.S. whites, 1993-2002. Cancer Epidemiol Biomarkers Prev. 2006;15:1515-1519.

30. Byers T. Four Corners Breast Cancer Study. National Cancer Institute 5R01CA078552-02. Available at: http://cancercontrol. cancer.gov/grants/abstract.asp?applid $=6173857$. Accessed on July 9, 2008.

31. Slattery ML, Edwards S, Murtaugh MA, et al. Physical activity and breast cancer risk among women in the southwestern United States. Ann Epidemiol. 2007;17:342-353.

32. Rubin CH, Lanier A, Socha M, Brock JW, Kieszak S, Zahm S. Exposure to persistent organochlorines among Alaska Native women. Int J Circumpolar Health. 2001;60:157-169.

33. Cowan LD, Go OT, Howard BV, et al. Parity, postmenopausal estrogen use, and cardiovascular disease risk factors in American Indian women: the Strong Heart Study. J Womens Health. 1997;6:441-449.

34. Steele CB, Cardinez CJ, Richardson LC, Tom-Orme L, Shaw KM. Surveillance for health behaviors of American Indians and Alaska Natives-findings from the Behavioral Risk Factor Surveillance System, 2000-2006. Cancer. 2008;113 (5 suppl):1131-1141.

35. U.S. Census Bureau. Facts for Features: American Indian and Alaska Native Heritage Month: November 2006 (CB06FF. 16). Washington, DC: Public Information Office, U.S. Census Bureau; 2006.

36. Ogunwole SU. We the People: American Indians and Alaska Natives in the United States: Census 2000 Special Reports. Washington, DC: U.S. Census Bureau; 2006.

37. Seattle Indian Health Board-Urban Indian Health Institute. The Health Status of Urban American Indians and Alaska Natives: An Analysis of Select Vital Records and Census Data Sources. Seattle, Wash: Seattle Indian Health BoardUrban Indian Health Institute; 2004.

38. Kaur JS. Migration patterns and breast carcinoma. Cancer. 2000;88:1203-1206.
39. Burhansstipanov L. Urban Native American health issues. Cancer. 2000;88:1207-1213.

40. Lanier AP, Kelly JJ, Maxwell J, McEvoy T, Homan C. Cancer in Alaska Native people, 1969-2003. Alaska Med. 2006;48:30-59.

41. Chao A, Becker TM, Jordan SW, Darling R, Gilliland FD, Key CR. Decreasing rates of cervical cancer among American Indians and Hispanics in New Mexico (United States). Cancer Causes Control. 1996;7:205-213.

42. Centers for Disease Control and Prevention, National Center for Chronic Disease Prevention and Health Promotion. National Breast and Cervical Cancer Early Detection Program, 2007. Atlanta, Ga: Centers for Disease Control and Prevention; 2007. Available at: http://www.cdc.gov/cancer/ nbccedp. Accessed on July 9, 2008.

43. Centers for Disease Control and Prevention, National Center for Health Marketing. Guide to Community Preventive Services Website. Available at: www.thecommunityguide.org. Accessed on July 9, 2008.

44. Roubideaux M, Russell T, Quisno J, et al. Satellite transmission of digital screening mammograms from American Indian reservations to an academic medical center: initial results. Presented at the Annual Meeting of the Radiological Society of North America, Chicago, Illinois, November 26 to December 1, 2006. Available at: http://rsna2006. rsna.org/rsna2006/V2006/conference/event_display.cfm? em_id=4438804. Accessed on July 9, 2008.

45. Swanson M, Lin C-S. Survival patterns among younger women with breast cancer: the effects of age, race, stage, and treatment. Monogr Natl Cancer Inst. 1994;16:69-77.

46. Yankaskas BC. Epidemiology of breast cancer in young women. Breast Dis. 2005-2006;23:3-8.

47. Janerich DT, Hoff MG. Evidence for a crossover in breast cancer risk factors. Am J Epidemiol. 1982;116:737-742.

48. Valentgas P, Daling JR. Risk factors for breast cancer in younger women. Monogr Natl Cancer Inst. 1994;16:15-22.

49. Ron E, Lubin F. Evidence for a crossover in breast cancer risk factors. Am J Epidemiol. 1984;119:139-141.

50. Lanier AP. Cancer incidence in Alaska Natives: comparison of 2 time periods, 1989-1993 versus 1969-1973. Cancer. 1998;83:1815-1817.

51. Lanier AP, Kelley JJ, Holck P, Smith B, McEvoy T. Alaska Native Cancer Update 1985-97 by Sex, Age, Service Unit and Year. Anchorage, Alaska: Alaska Native Epidemiology Center; 2000.

52. Kaur JS, Roubidoux MA, Sloan J, Novotny P. Can the Gail model be useful in American Indian and Alaska Native populations? Cancer. 2004;100:906-912.

53. Amey CH, Miller MK, Albrecht SL. The role of race and residence in determining stage at diagnosis of breast cancer. J Rural Health. 1997;13:99-108.

54. Barry J, Breen N. The importance of residence in predicting late-stage diagnosis of breast or cervical cancer. Health Place. 2005;11:15-29.

55. Lee-Feldstein A, Feldstein PJ, Buchmueller T, Katterhagen G. The relationship of HMOs, health insurance, and delivery systems to breast cancer outcomes. Med Care. 2000; 38:705-718.

56. Menck HR, Mills PK. The influence of urbanization, age, ethnicity, and income on the early diagnosis of breast carcinoma. Cancer. 2001;92:1299-1304.

57. Taplin SH, Ichikawa L, Yood MU, et al. Reason for latestage breast cancer: absence of screening or detection, or breakdown in follow-up? J Natl Cancer Inst. 2004;96:15181527. 
58. Hunter CP. Epidemiology, stage at diagnosis, and tumor biology of breast carcinoma in multiracial and multiethnic populations. Cancer. 2000;88(suppl):1193-1202.

59. Frost F, Taylor V, Fries E. Racial misclassification of Native Americans in a surveillance, epidemiology, and end results cancer registry. J Natl Cancer Inst. 1992;84:957962.

60. Partin MR, Rith-Najarian SJ, Slater JS, Korn JE, Cobb N, Soler JT. Improving cancer incidence estimates for American Indians in Minnesota. Am J Public Health. 1999;89: 1673-1677.

61. Kwong S, Perkins C, Snipes K, Wright W. Improving American Indian cancer data in the California Cancer Registry by linkage with the Indian Health Service. J Registry Manage. 1998;25:17-20.

62. Sugarman JR, Holliday M, Ross A, Castorina J, Hui Y. Improving American Indian cancer data in the Washington State Cancer Registry using linkages with the Indian Health Service and tribal records. Cancer. 1996;78(7 suppl):1564-1568.

63. Gomez SL, Glaser SL. Misclassification of race/ethnicity in a population-based cancer registry. Cancer Causes Control. 2006;00:1-11.

64. Clegg LX, Reichman ME, Hankey BF, et al. Quality of race, Hispanic ethnicity, and immigrant status in populationbased cancer registry data: implications for health disparity studies. Cancer Causes Control. 2007;18:177-187. 